\title{
DOS INSCRIPCIONES ÁRABES MODERNAS EN MONTAÑAS DE ALICANTE
}

Por

LEONOR CARMEN RODRIGUEZ MARTINEZ

Quizás estemos más acostumbrados a escuchar alguna noticia esporádica, sobre el descubrimiento arqueológico de restos árabes sepultados por múltiples construcciones posteriores, o perdido por el desconocimiento, fruto de ocho siglos de convivencia. Lo que hoy vamos a estudiar aquí es mucho más próximo, y también extraño. Se trata de dos inscripciones árabes modernas que han sido descubiertas en nuestra provincia.

La que primero nos ocuparemos, ha sido redescubierta recientemente por el arquitecto alicantino Màrius Bevià. Se encuentra junto al Balneario de Aigües de Busot, casi en la cumbre de una montaña. La segunda está en la Sierra de Orihuela, en el monte conocido como Cabezo del Castillo por albergar los restos de un antiguo castillo.

Estos ejemplos no podían pasar desapercibidos por mucho tiempo para la Universidad de Alicante, y así, bajo la dirección del profesor Míkel de Epalza y del profesor Fernando de Lassala, historiador y profesor del Colegio de la Inmaculada, iniciamos su estudio, con la finalidad de desentrañar su significado e investigar la posibilidad de que ambas tuviesen una conexión. Y esto es precisamente lo que nosotros intentaremos mostrar aquí.

\section{Inscripción de Aigües}

Desde comienzos del siglo XVIII, las aguas termales de Aguas de Busot (actualmente municipio de Aigües) gozaron de reconocida fama, tanto es así, que en 1816 la Marquesa del Bosch, Condesa de Torrellano, adquirió los baños, construyendo un balneario aristocrático que hizo incrementar la población en tal proporción que en 1841 Aguas de Busot se segregaba del Municipio de Alicante para constituirse en Ayuntamiento independiente.

Posteriormente, en la década de los 90 , se construiría un nuevo edificio, el que hoy se conserva. Su importancia iría creciendo a lo largo de los 


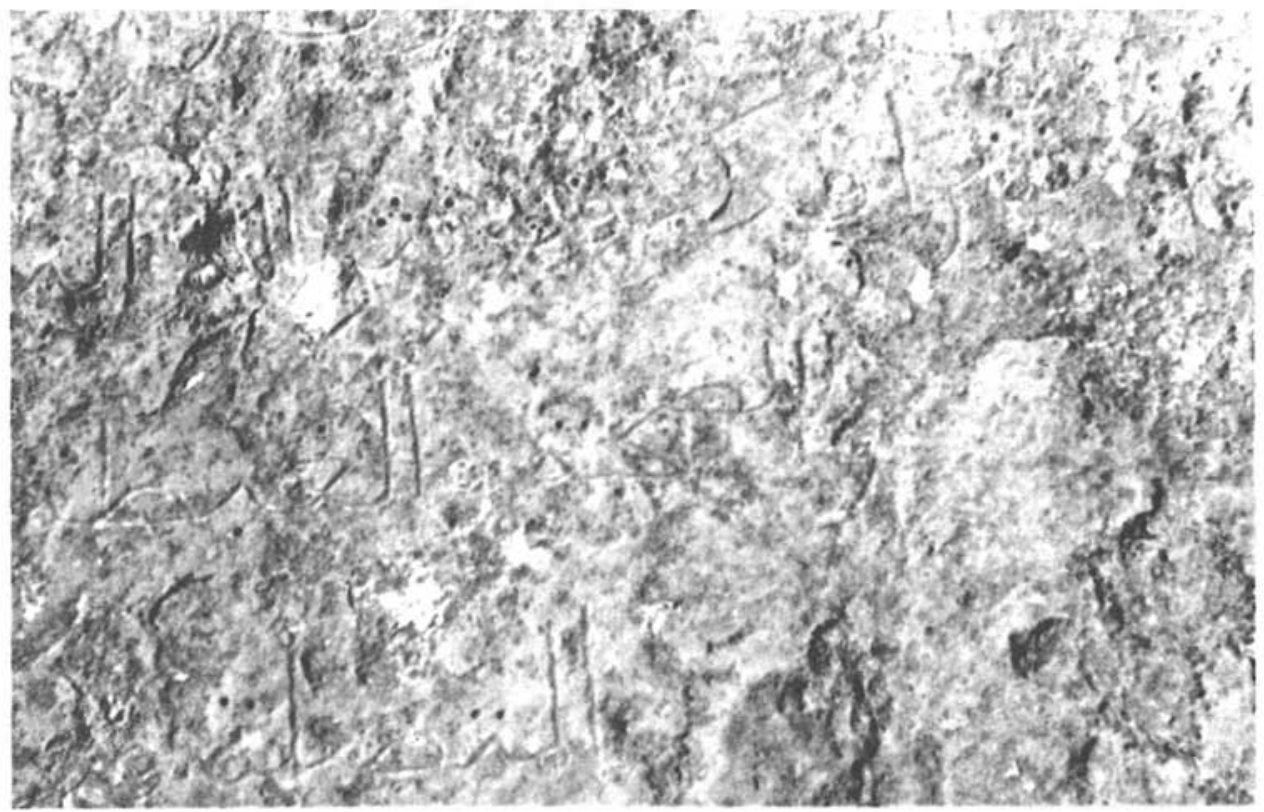

1.- Inscripción de Aigües.

decenios siguientes, hasta que las circunstancias lo convirtiesen de lujosa residencia en Preventorio Infantil Antituberculoso del Estado, en 1936, para ser definitivamente cerrado por su falta de rentabilidad en 1967.

Ya desde mediados del siglo pasado se conocía su utilización en época romana; sus aguas curativas servían para mejorar entre otras dolencias el reumatismo. Los romanos dejaron ruinas de escalinatas, acueductos, columnas, pilas y monedas con el busto de Julio César, aunque había algunos que se preguntaban si su fundación no sería anterior a este momento. Siguiendo esta línea, se podría pensar si los árabes, en su afán por instalarse en las tan necesarias fuentes de agua, no habrían escogido también este lugar tan propicio.

El lugar, situado a un kilómetro del pueblo de Aigües, a cuatro del de Busot y a diez de Relleu, presenta una topografía eminentemente montañosa. Las cimas del Garroferet, peña Rocha, etc., configuran un semicírculo abierto al sureste. La Sierra de Aitana, el Puig Campana y la cotas mediterránea también son divisables desde aquí.

Las propiedades de las aguas termales estaban indicadas para el reuma, afecciones del estómago y genito-urinarias, matriz, vías respiratorias, anemia y neurastenia, entre otras. El Balneario funcionaba mediante un sistema de concesión, y en la época en que era estación médica, sanatorio y termas, un médico-director especialista reglamentaba la organización, estableciendo el plan de vida.

El Hotel Miramar constituía la principal instalación. Edificio rectangular, estaba ocupado en el piso bajo por las salas hidroterápicas (estufas, pilas, du- 
chas, piscinas, vestuarios, un sistema de circulación de agua caliente y fría, y hasta una gruta artificial de estalactitas), y en los tres pisos superiores por las habitaciones. En el momento de su construcción supuso un verdadero hito, no se reparó en los gastos y contó además con los medios técnicos e higiénicos más avanzados. Para el esparcimiento se sumaba a un completo $\mathrm{Ca}-$ sino, a un parque que rodeaba el edificio, y a un bosque de pinares donde se construyeron numerosos hoteles para familias particulares.

Antes de convertirse en Preventorio se pensó en la posibilidad de crear allí un sanatorio, por la situación geográfica tan propicia del lugar. Son numerosos los especialistas que a través de su testimonio intentaron convecer al Marqués del Bosch de este propósito.

El Balneario de Aguas de Busot fue siempre un lugar famoso, y aparecen frecuentemente noticias en la prensa sobre él. Desde finales del siglo XIX hasta la Guerra Civil encontramos diversidad de ellas; anuncios propagandísticos se suceden día a día a lo largo de los años en los periódicos de dispar ideología política, notas de sociedad que informan del viaje de algún personaje importante de la vida social de la provincia o de la Corte, que se desplaza hasta aquí en busca de reposo o curación. El período de máximo esplendor lo alcanzó el Balneario desde 1924 hasta 1929. Posteriormente, el retroceso sería muy importante. Las causas son varias: la competencia ejercida por otros balnearios cercanos que empiezan a potenciarse ahora; la campaña a favor de los «baños de sol», es decir, de las playas; el que Alicante comenzaría a partir de ahora a absorber un contingente numeroso de gente procedente del interior de la península, y en definitiva una modificación en los gustos y preferencias de la población. Eso hará que poco a poco su rentabilidad disminuya, hasta ser cerrado.

De forma cualitativa, el grupo social que de manera más apreciable frecuenta este lugar, será la burguesía media-alta; comerciantes y banqueros de la provincia, médicos y altos funcionarios, algunos militares que proceden del Norte de Africa en el momento de las campañas de Primo de Rivera, y también políticos e intelectuales, como Giner de los Ríos, asiduo visitante y siempre dispuesto a elogiar las excelencias del lugar, Torcuato Luca de Tena, los ministros Lerroux y Antonio Goicoechea o el diputado radical Marcelino Domingo. Junto a estos nombres habría que destacar el de algunos aristócratas.

Era además lugar de celebraciones sociales y fiestas, bailes de disfraces, el carnaval, la noche de San Juan o la Noche Vieja, en los que se facilitaba el transporte desde Alicante. El Restaurante también se había convertido en un centro preferencial para determinados actos.

El Doctor Valenzuela en el estudio realizado en 1897, comentaba, como dato anecdótico, la afición de algunos artistas a dejar testimonio de su obra entre las piedras del bosque que rodea el recinto, durante su estancia en el lugar. Así, Vicente Bañuls, autor de la estatua de Maisonnave, había esculpido el busto de un sátiro; Cabrera y Cantó había pintado, en el fondo de una roca, un par de palomos en amoroso arrullo, posados sobre la rama de un almendro; Antón, entonces joven pintor alcoyano, esbozó un San Jerónimo en el rincón de una gruta. No sabemos si en este ambiente podríamos incluir la inscripción hallada cerca del Balneario. 
La montaña en cuyas laderas se asienta el Balneario está un poco más en alto que el pueblo y forma un cerco montañoso, excepto por el sureste, que deja paso a una vista sobre la Bahía de Campello y luego a la de Alicante. Uno de los picos, al Noroeste del edificio, es el que alberga la inscripción que hoy nos ocupa.

Sobre una gran roca, que pasa desapercibida al visitante, aparece trabajada sin ningún tipo de preparación, ayudándose sólo con algún instrumento técnico, quizás un cincel. Los trazos han quedado un poco desdibujados por la naturaleza de la piedra.

Se trata de un texto con grafía propia de las escrituras orientales. Debe ser considerada contemporánea, según ha hecho ver el arabista Dr. Mikel de Epalza, rechazando de pleno la posibilidad de que se tratase de uno de los restos de la dominación árabe de siglos atrás.

La inscripción comienza con unas palabras en alabanza de Dios, que si bien es el ínicio de casi todos los capítulos o Azoras del Corán, ha sido alterada para introducir una serie de elementos nuevos, algo que por otra parte es completamente irregular, e impensable para un musulmán, puesto que, como es conocido, el Corán, el libro Sagrado, no puede ser modificado.

La frase final, la despedida, es una bendición. El autor ha utilizado aquí unas expresiones que generalmente se dirigen al Profeta Mahoma o a Dios, para aplicarlas a un interlocutor moderno. Todo esto, sumado al hecho de que no aparece en ningún momento referencia alguna al Islam, lo hace parecer casi blasfematorio. El sentido ha sido cambiado y el significado es puramente espiritual.

La traducción aproximada podría quedar así:

«En nombre de Dios, El Clemente, El Misericordioso.

¡Oh lugar admirable y hermoso!

Mi mirada abarca los cielos, la tierra

y el mar desde tu altura.

Dios ha distribuido la gracia,

la salud y la felicidad relacionados contigo.

Dios te (hueco por desconchado de la roca).

Y bendiga a tu familia y la salve con salvación perfecta.»

\section{Inscripción de Orihuela}

En este marco hay que incluir la segunda inscripción. Encontrada en el monte llamado «Cabezo del Castillo», está situado a la espalda de la antigua Universidad, después Colegio de los Jesuitas, entre 1872 y 1956, actualmente de la Diócesis de Orihuela-Alicante, con el mismo nombre que se conoce hoy "Santo Domingo", sigue ejerciendo las funciones de Colegio.

Con dirección Sureste, la inscripción se orienta al Norte del Cabezo, que forma junto a otras montañas una sierra que descansa sobre la Vega Baja del Segura.

El proceso técnico se repite: grafía oriental, sobre la roca, sin preparación, pero presenta ahora unos trazos más bastos que en el ejemplo de Aigües. La causa de esta irregularidad en las letras, es que el autor no se ha ayudado por ningún instrumento cortante de los utilizado generalmente para trabajar la piedra. 


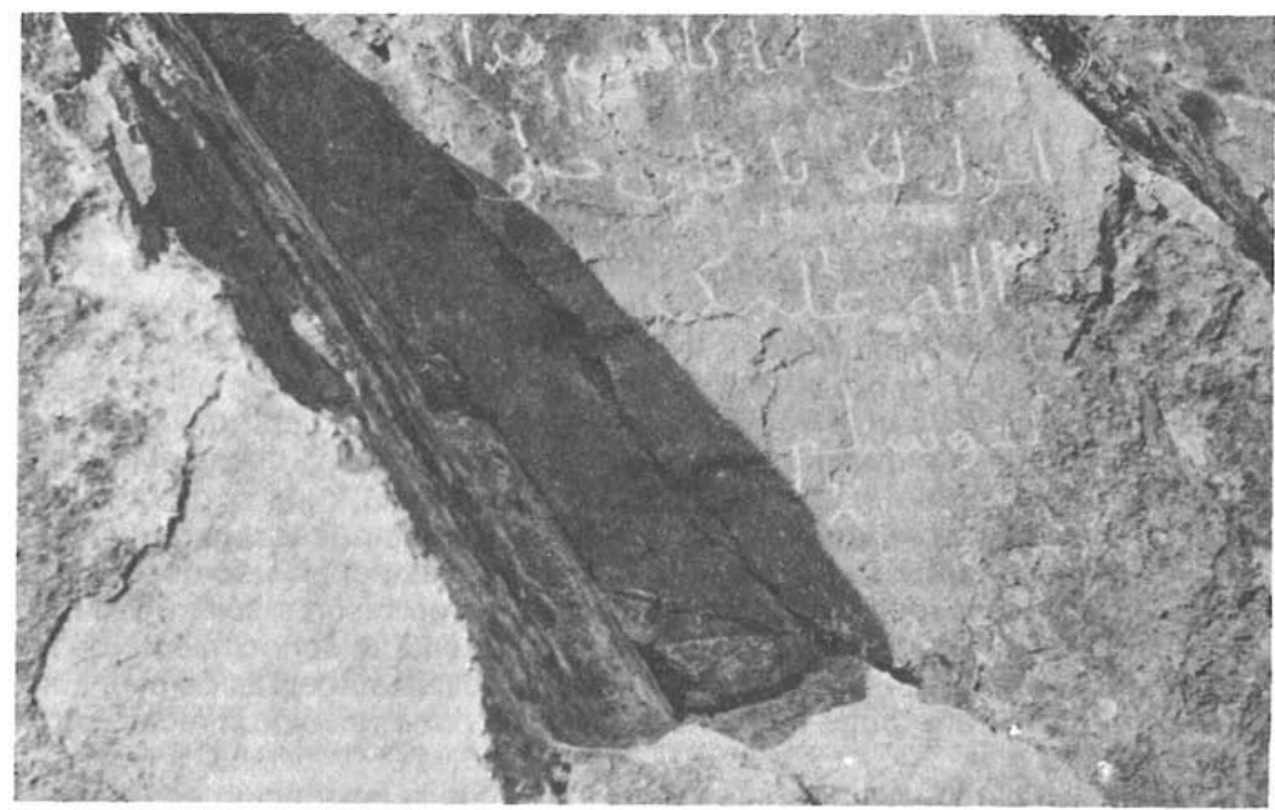

2.-Inscripción de Orihuela.

Su paternidad ha sido atribuida tradicionalmente, por las lenguas populares, al jesuita Padre Furgus. Presenta ciertos elementos que la van a emparentar con la de Aigües de Busot.

Es un texto mucho más corto: únicamente cuatro líneas. En esencia recoge una bendición, en nombre de Dios, dirigido a una persona, al parecer una mujer que podría llamarse Flora. Otra vez se ha utilizado una escritura, la árabe para expresar un mensaje que no sólo no guarda relación con esa cultura, sino que además se contrapone. La traducción sería así:

"Dónde (abākās) ésto?

Yo te digo, joh Flora!: Dios te bendiga y te salve.»

Si nos centramos en el posible autor de esta inscripción, en el Padre Furgus, descubriremos algunas notas interesantes. Nacido en Agen (Toulouse), en 1856, su verdadero apellido era Fourgous, ortografía que cambió, por ser más fácil así su pronunciación en España. Siendo él niño, su familia se trasladó a Tarragona, y posteriormente a Barcelona. Entró en el noviciado jesuita de Dussede (Francia), donde rápidamente se distinguió en los estudios de lenguas y literatura. Llegó a hablar varios idiomas modernos y, entre los antiguos, latín, griego, hebreo y árabe. Humanista, orador, teólogo y matemáti$\mathrm{co}$, fue profesor en distintos centros, para trasladarse finalmente a Orihuela, por benigno clima, puesto que siempre había padecido de una salud débil. Inició investigaciones por aquellas tierras con la finalidad de encontrar restos árabes, anhelo que no alcanzó, aunque sí se convirtió en una gran especialista en Prehistoria. Encontró varias necrópolis, en las que estudió el sistema de inhumación. Con los materiales que había recogido creó el Museo Arqueó- 
logo. Así estudió las excavaciones de Tarifa, con restos romanos, la de Calaciete (Teruel), rica en hallazgos celtas, o la estación árabe de María de Huerva en Zaragoza.

El erudito se despeñaría en la Sierra de Orihuela, a espaldas del Colegio, muy cerca del lugar donde se encuentra la inscripción que ahora estamos estudiando, y fue encontrado en la cueva de Lourdes, en enero de 1909.

\section{Autoría de las Inscripciones}

Para llegar a conocer el autor de la inscripción de Orihuela hemos de tener en cuenta dos factores decisivos: por una parte la situación geográfica, detrás del Colegio de Santo Domingo, en un lugar conocido como el "Merendero", una especie de mirador construido a modo de repisa desde el que se puede disfrutar de unas vistas muy bellas de parte de la Vega, y que resulta enormemente accesible, gracias a unas escaleras construidas que parte desde la misma fachada posterior del Colegio. Según las noticias de que disponemos fue un lugar muy frecuentado, ya que los profesores solían visitarlo y reunirse alli. Por otra parte, hay que tener en cuenta el conocimiento de la lengua árabe que tenía el Padre Furgus, gran entusiasta además de esta cultura. No sería extraño pues que estableciésemos una relación directa entre ambos hechos.

Más difícil parece llegar a conocer el autor que la inscripción de Aigües. No queda constancia de en qué momento fue realizada, el motivo y a quién puede ser atribuida. Quizás esté dentro de la dinámica de un juego, igual que el que seguían los otros artistas citados, con el propósito de embellecer el paisaje, o el de ocupar los ratos de ocio. Es cierto que no tenemos ninguna noticia que pueda situar al erudito de Orihuela en el Balneario de Aigües de Busot, pero si tenemos en cuenta que su salud era delicada, no sería impensable que hubiese realizado al menos una visita al lugar en algún momento de su vida.

Gracias a un artículo que amablemente nos proporcionó el Padre Fernando de Lassala, llegamos a conocer un estudio realizado pro el Padre Furgus sobre un jarrón de procedencia no esclarecida; bien podría ser de Granada o de Toledo, que el erudito fijaba en la última época del arte de la Alhambra. Además de la Cronología de la obra, el padre Furgús detallaba las dimensiones de la pieza, el material, su decoración, junto a la traducción de unos grafitis que aparecian adornando el cuerpo de la vasija. Curiosamente esta pieza había sido donada por su propietario, el Marqués del Bosch, como se recordará también propietario del Balneario de Aigües de Busot, al museo del Colegio de Santo Domingo, que dirigía el Padre Furgús. No conocemos si existía una previa relación de amistad entre ambos hombres, solamente las palabras de agradecimiento que le dirige el erudito, que además le llama "...insigne bienhechor...n.

Podría ser que este ilustre personaje alicantino hubiese sido en su día alumno en el Colegio de Orihuela, y, como era práctica frecuente, con el paso de los años hubiese mostrado su recuerdo con un regalo que sería bien acogido y se reconocería el mérito. Otra posibilidad sería que ambos, el Marqués del Bosch y el Padre Furgús, hubiesen trabado conocimiento por otros conductos. 
Por último, el análisis de ambos textos permite establecer muchas conexiones entre ellos: una grafía oriental, igual construcción en las frases, y sobre todo, un transfondo del texto coránico sin ninguna referencia al Islam, que aplica a un interlocutor moderno unas expresiones generalmente dirigidas al Profeta Mahoma o a Dios, impensable en un musulmán culto. Sería mucha coincidencia pensar que dos personas distintas se hubiesen encargado de escribir dos textos, separados geográficamente, de igual forma. La opinión de los Dres. Epalza y Rubiera, a la vista de ambas escrituras, es que se trata de un mismo autor, tanto por su caligrafía y técnica de distribución del texto sobre la pared de la roca como por el estilo árabe del escrito.

\section{BiBliografía}

ANONIMO: "Análisis quimico de las aguas termo-potables de los Baños de Busot", 1815.

BARBERA, F.; "Las víctimas de la Ciencia". Revista Valenciana de Ciencias Medicas. Tomo IX. Números 194, 195 y 196

FERNANDEZ LOPEZ, J.: "Opúsculos médicos. Aguas minerales de Busot», 1849.

FURGUS, JULIO: "Arte Mahometano". Revista "Razón y Fen. n. 19. Pág. 509-514. Madrid 1907.

LA ILUSTRACION ESPAÑOLA Y AMERICANA. N. ${ }^{\circ} X I X$. Pág. 303. Madrid, mayo 1899.

.AMOS, VICENTE: «Historia de la provincia de Alicante y de su capital». Excma. Diputación Provincial. Alicante 1971

SEIJO ALONSO, FRANCISCO: «Balnearios y aguas medicinales de Castellón, Valencia y Alicante». Ediciones Seijo. Alicante 1978.

VALENZUELA: "Estación médica de invierno y sanatorio permanente para el tratamiento climatológico de las entermedades del pecho y para la curación de la tuberculosis por el régimen higiénico. Busot (Alicante)». Madrid, 1897.

HEMEROTECA: Periódicos diarios de Alicante.

-. «EL LUCHADOR». Desde 1913 hásta 1924 ambos inclusive, 1936.

- "LA LIBERTAD REGIONAL DE ALICANTE». 1897 a 1900

- "DIARIO DE ALICANTE". De 1925 a 1929

- "MAS DIARIO DE LA MAÑANA". 1936. 